\title{
Sistem Pendukung Keputusan Untuk Penerimaan Beasiswa Dengan Metode Simple Additive Weighting (SAW) Pada Smkn 1 Ciomas Kabupaten Bogor
}

\author{
Yahdi Kusnadi ${ }^{*}$ ), Muhammad Wildan Dwiyansyah ${ }^{2)}$ \\ ${ }^{1)}$ Program Studi Sistem InformasiAkuntansi, Universitas Bina Sarana Informatika \\ 2) Program Studi Sistem Informasi, Sekolah Tinggi Manajemen Informatika dan Komputer Nusa Mandiri \\ ${ }^{*}$ Correspondence author: yahdi.ydk@ bsi.ac.id, DKI Jakarta, Indonesia
}

\begin{abstract}
Abstrak
Sebagai lembaga pendidikan formal, SMKN 1 Ciomas merupakan salah satu sekolah yang memberikan beasiswa kepada para siswa. Beasiswa ini ditujukan untuk siswa kurang mampu. Untuk bisa mendapatkan beasiswa tersebut, siswa harus memenuhi kriteria-kriteria yang ditetapkan oleh SMKN 1 Ciomas. Kriteriakriteria tersebut antara lain surat keterangan tidak mampu, status anak dalam keluarga, penghasilan orangtua, jumlah tanggungan orangtua, dan nilai rata-rata raport semester terakhir. Hanya siswa yang memenuhi kriteria-kriteria tersebut yang dapat memperoleh beasiswa. Untuk membantu penentuan dalam menetapkan seseorang yang layak menerima beasiswa maka dibutuhkan sebuah sistem pendukung keputusan. Sistem pendukung keputusan berbasis komputer merupakan salah satu cara untuk membantu permasalahan penyeleksi penerima beasiswa tersebut. Oleh karena itu perlu dibangun sistem pendukung keputusan untuk penerimaan beasiswa dengan menggunakan metode Simple Additive Weighting (SAW) yang mempunyai kemampuan untuk memecahkan masalah multikriteria. Dari hasil pengujian, diperoleh kesimpulan bahwa sistem pendukung keputusan untuk penerimaan beasiswa ini telah berhasil dikembangkan dan menampilkan perankingan dari hasil penyeleksian para calon penerima beasiswa.
\end{abstract}

Kata Kunci: Beasiswa, Sistem Pendukung Keputusan, SAW

\begin{abstract}
As formal education institutions, SMKN 1 Ciomas is one school that provides scholarships to students. This scholarship is intended for disadvantaged students. To be eligible for the scholarship, students must meet the criteria set by SMKN 1 Ciomas. These criteria include a certificate can not afford, the status of children in the family, parental income, number of dependents of parents, and the average value of the last semester report cards. Only students who meet the criteria to obtain a scholarship. To assist in determining a person determining the eligible then takes a decision support system. Computer-based decision support system is one way to help the problems of the grantee selectors. Therefore, it is necessary to build a decision support system for receiving a scholarship by using Simple Additive weighting method (SAW) which has the ability to solve the problem of multiple criteria. From the test results, we concluded that the decision support system for receiving this scholarship has been successfully developed and display the ranking of the results of the selection of the scholarship recipients.
\end{abstract}

Keywords: Scholarship, Decision Support Systems, SAW

\section{PENDAHULUAN}

Sekolah Menengah Kejuruan Negeri 1 Ciomas adalah sebuah lembaga pendidikan di Kabupaten Bogor Provinsi Jawa Barat. Sebagai lembaga pendidikan formal, SMKN 1 Ciomas merupakan salah satu sekolah yang memberikan beasiswa kepada para siswa. Beasiswa ini ditujukan untuk siswa kurang mampu. Dengan adanya beasiswa ini diharapkan dapat membantu siswa yang kurang mampu dalam memenuhi kebutuhan 
sekolah. Selain itu, beasiswa tersebut juga diharapkan dapat memacu siswa kurang mampu tersebut agar berusaha tetap berprestasi.

Menurut (Helilintar, 2016) menyimpulkan bahwa, menyadari bahwa pendidikan sangat penting, Negara sangat mendukung setiap warga negaranya untuk meraih pendidikan setinggi-tingginya. Melakukan program pendidikan gratis dan program beasiswa. Beasiswa dapat dikatakan pembiayaan yang tidak bersumber dari pendanaan sendiri atau orang tua, akan tetapi diberikan oleh pemerintah, perusahaan swasta, kedutaan, universitas, serta lembaga pendidik. Biaya tersebut diberikan kepada yang berhak menerima sesuai dengan kriteria yang ditentukan.

Untuk bisa mendapatkan beasiswa tersebut, siswa harus memenuhi kriteria-kriteria yang ditetapkan oleh SMKN 1 Ciomas. Kriteria-kriteria tersebut antara lain surat keterangan tidak mampu, status anak dalam keluarga, penghasilan orangtua, jumlah tanggungan orangtua, dan rata-rata nilai raport semester terakhir siswa. Hanya siswa yang memenuhi kriteria-kriteria tersebut yang dapat memperoleh beasiswa. Oleh karena jumlah siswa yang mengajukan beasiswa banyak, sedangkan beasiswa yang tersedia jumlahnya terbatas, maka pihak SMKN 1 Ciomas membentuk penyeleksi penerima beasiswa. Namun penyeleksi tersebut masih menggunakan sistem manual yang dirasa kurang efektif dan efisien. Sehingga perlu dibangun sebuah sistem yang efektif dan efisien untuk bisa menentukan siswa yang layak mendapatkan beasiswa.

Menurut (Hidayat, 2017) menyimpulkan bahwa, selama proses pengambilan keputusan penerimaan beasiswa masih dilakukan secara konvensional, sering adanya kerangkapan data dan tidak valid. Hasil berupa keputusan penerima beasiswa tidaklah sesuai dengan harapan, misalnya siswa yang kurang berprestasi malah mendapatkan beasiswa dan siswa yang seharusnya mendapatkan beasiswa malah tidak mendapatkan beasiswa. Proses penyeleksian ini membutuhkan ketelitian dan waktu karena data siswa akan dibandingkan dengan kriteria beasiswa satu persatu.

Sistem Pendukung Keputusan (SPK) merupakan suatu sistem yang dapat membantu seseorang dalam meningkatkan kinerjanya dalam pengambilan keputusan. Nilai dari datadata kriteria dalam kasus ini biasanya berupa kisaran dalam jangkauan nilai tertentu. Oleh karena itu, SPK ini menggunakan metode Simple Additive Weighting (SAW). Metode ini menentukan nilai bobot untuk setiap atribut, yang dilanjutkan dengan proses perankingan. Sehingga akan menghasilkan alternatif terbaik dari banyak alternatif dengan perhitungan yang cukup tepat. Alternatifnya adalah siswa calon penerima beasiswa yang akan diseleksi berdasarkan kriteria-kriteria yang telah ditentukan. 
Menurut (Frieyadie, 2017) menyimpulkan bahwa, metode Simple Additive Weighting membantu pengambilan keputusan memilih sebuah alternatif yang memberikan hasil paling mendekati tujuannya. Tujuan penelitian ini untuk membantu tim penyeleksi beasiswa menentukan siswa yang lebih berhak mendapatkan beasiswa; penentuan beasiswa menjadi lebih teliti dan sesuai kriteria dalam penyeleksian penerima beasiswa, membantu para penyeleksi mendapatkan waktu yang dibutuhkan dalam penyeleksian penerima beasiswa.

Menurut Alter dalam Kadir (2014:108) menyimpulkan bahwa, Sistem Pendukung Keputusan (SPK) atau Decision Support Systems (DSS) adalah sistem informasi interaktif yang menyediakan informasi, pemodelan, dan pemanipulasian data yang digunakan untuk membantu pengambilan keputusan pada situasi yang semiterstruktur dan situasi yang tidak terstruktur dimana tak seorang pun tahu secara pasti bagaimana keputusan seharusnya dibuat.

Menurut Novriansyah (2014:11) menyimpulkan bahwa, metode Simple Additive Weighting sering juga dikenal dengan istilah metode penjumlahan berbobot. Konsep dasar metode Simple Additve Weighting adalah mencari penjumlahan terbobot dari rating kinerja pada setiap alternatif pada semua atribut. Metode Simple Additive Weighting disarankan untuk menyelesaikan masalah penyeleksian dalam sistem pengambilan keputusan multi proses. Metode Simple Additive Weighting merupakan metode yang banyak digunakan dalam pengambilan keputusan yang memiliki banyak atribut. Metode Simple Additive Weighting membutuhkan proses normalisasi matriks keputusan $(\mathrm{x})$ ke suatu skala yang didapat diperbandingkan dengan semua rating alternative yang ada.

\section{METODE}

Dalam penelitian ini, diuraikan mengenai langkah-langkah yang dilakukan menggunakan metodologi penelitian yang terarah dan memudahkan dalam melakukan analisa terhadap permasalahan yang ada. Berikut merupakan bagian dari tahapan penelitian seperti yang terlihat pada gambar 1 dibawah ini: 


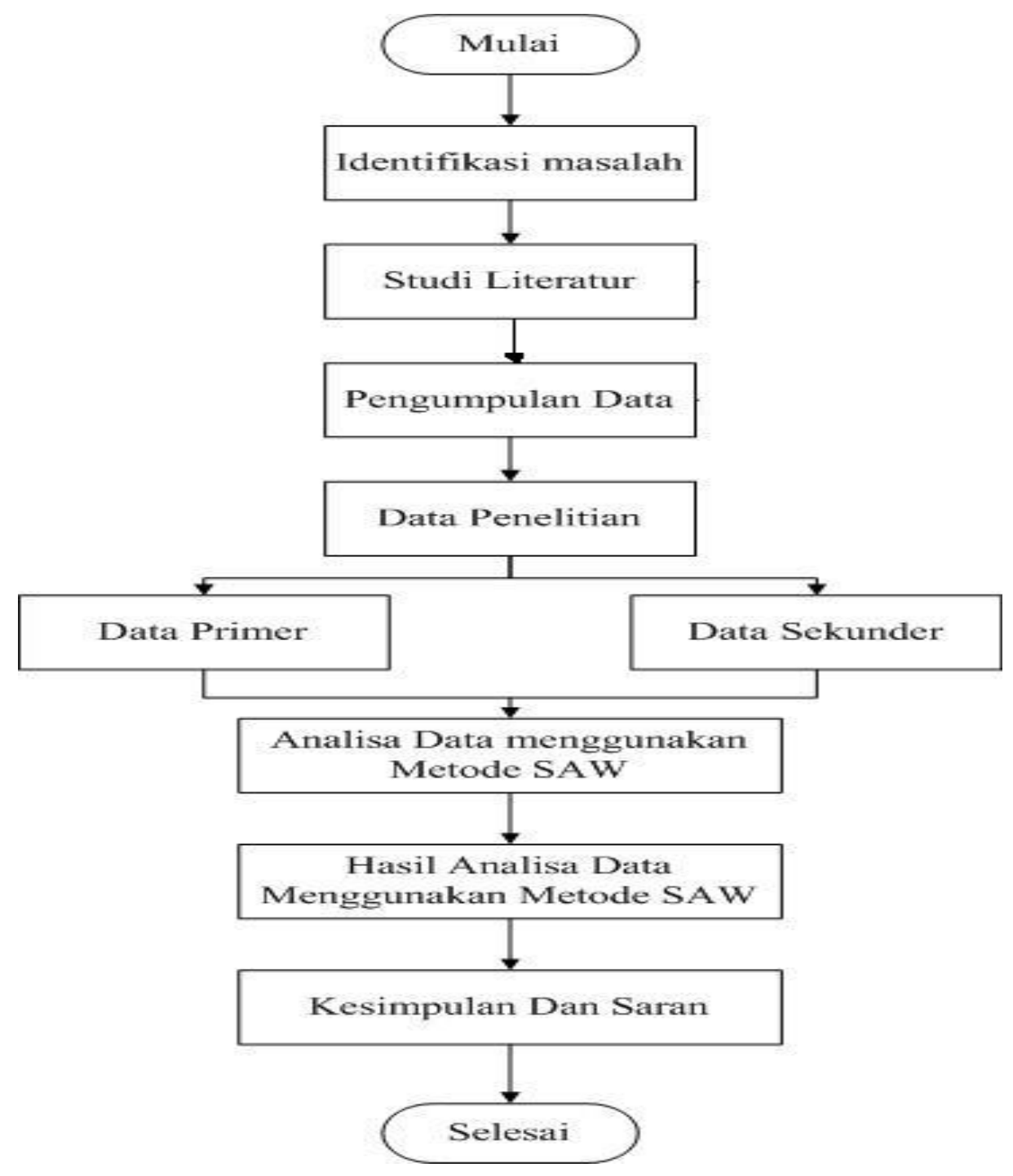

Gambar 1. Flowchart Langkah-Langkah Penelitian Sumber: Fiqih dan Yahdi Kusnadi (2017:43)

Metode Pengumpulan data merupakan faktor penting demi keberhasilan penelitian. Hal ini berkaitan dengan bagaimana cara mengumpulkan data. Siapa sumbernya, dan alat apa saja yang digunakan. Penelitian ini menggunakan metode pengumpulan data sebagai berikut:

1. Data Primer: Menurut Abdillah (2018:103) "Data Primer adalah data yang belum pernah diolah oleh pihak tertentu. Data primer menunjukkan keaslian informasi yang terkandung di dalam data tersebut". Dalam pengumpulan data primer pada penelitian ini digunakan metode observasi dan wawancara.

2. Data Sekunder: Menurut Abdillah (2018:104) "Data Sekunder adalah data yang telah diolah, disimpan, disajikan dalam format atau bentuk tertentu oleh pihak tertentu untuk kepentingan tertentu". Sedangkan pengumpulan data sekunder dalam 
penelitian ini menggunakan buku, jurnal, publikasi dan lain-lain. Peneliti mengumpulkan data dan informasi melalui studi pustaka yang bersifat sekunder, yaitu data-data yang diperoleh melalui buku-buku referensi, dokumentasi, literatur, buku, jurnal, dan informasi lainnya yang ada hubungannya dengan masalah yang diteliti.

Untuk mencapai tujuan penelitian maka analisis yang digunakan adalah analisis data kualitatif dan analisis data kuantitatif. Analisis data kualitatif merupakan suatu analisis data yang digunakan apabila data terkumpul tidak dapat diangkakan, dalam artian hanya berupa uraian kata. Sedangkan analisis data kuantitatif merupakan suatu analisis data yang dipergunakan apabila kesimpulan-kesimpulan yang diperoleh dapat dibuktikan dengan angka-angka dan juga dalam perhitungan rumus yang ada hubungannya dengan analisis penelitian.

Penelitian menggunakan analisis Simple Additive Weighting (SAW) sering juga dikenal istilah metode penjumlahan terbobot. Konsep dasar SAW adalah mencari penjumlahan terbobot dari rating kinerja pada setiap alternatif pada semua atribut atau kriteria. Metode SAW membutuhkan proses normalisasi matriks keputusan (X) ke suatu skala yang dapat dibandingkan dengan semua rating alternatif yang ada. Nilai preferensi (Vi) diperoleh dari penjumlahan pada perkalian elemen baris matriks ternormalisasi (R) dengan bobot preferensi (W) yang bersesuaian dengan elemen kolom matriks. Proses perangkingan diperoleh berdasarkan alternatif yang memiliki nilai total terbesar sampai terendah sebagai penentuan siswa yang berhak menerima beasiswa.

Formula untuk melakukan normalisasi adalah sebagai berikut:

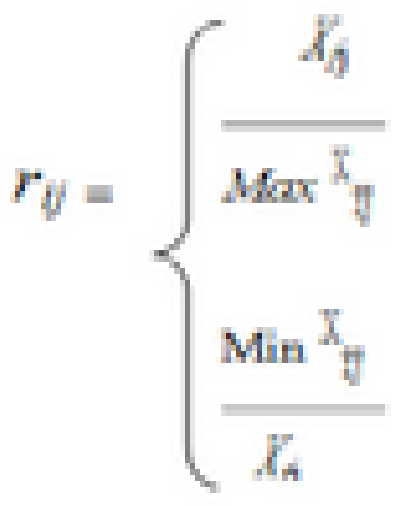

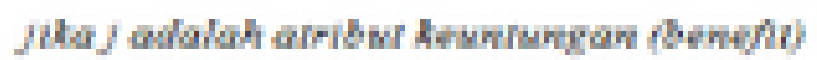

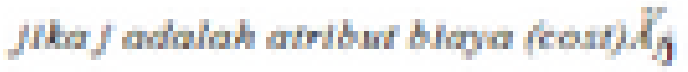

Gambar 2. Formula Untuk Melakukan Normalisasi

Sumber: Nofriansyah (2014:11) 
Dimana dengan rij adalah rating kinerja ternormalisasi dari alternatif Ai pada atribut $\mathrm{Cj}: \mathrm{i}=1,2 \ldots, \mathrm{m}$ dan $\mathrm{j}=1,2 \ldots, \mathrm{n}$

Keterangan

- Max Xij = Nilai terbesar dari setiap kriteria $\mathrm{i}$.

- Min Xij = Nilai terkecil dari setiap kriteria $\mathrm{i}$.

- Xij = Nilai atribut yang dimiliki dari setiap kriteria.

- Benerfit = Jika nilai terbesar adalah terbaik.

- Cost $\quad=$ Jika nilai terkecil adalah terbaik.

Nilai preferensi untuk setiap alternatif (Vi) diberikan rumus sebagai berikut:

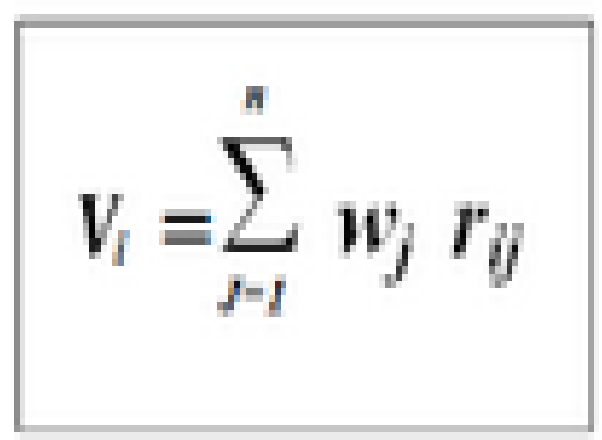

Gambar 3. Rumus Nilai Preferensi (Vi)

Sumber: Novriansyah (2014:12)

\section{Keterangan:}

$\mathrm{Vi} \quad=$ Rangking untuk setiap alternatif.

$\mathrm{Wj} \quad=$ Nilai bobot rangking (dari setiap kriteria).

rij $\quad=$ Nilai rating kinerja ternormalisasi.

\section{HASIL DAN PEMBAHASAN}

Ada beberapa langkah untuk melakukan perhitungan menentukan keputusan penerimaan beasiswa menggunakan Simple Additive Weighthing (SAW).

\section{Alternatif}

Langkah pertama menentukan alternatif, berikut adalah data alternatif yang digunakan dalam perhitungan pada Tabel 1 . 
Tabel 1. Data Alternatif

\begin{tabular}{|c|c|c|c|c|c|c|}
\hline \multirow{2}{*}{ No } & \multirow{2}{*}{ Nama } & \multicolumn{5}{|c|}{ Kriteria } \\
\hline & & SKTM & SADK & $\mathrm{PO}$ & JTO & NRRST \\
\hline 1 & $\begin{array}{l}\text { Abdul } \\
\text { Hakim }\end{array}$ & Ada & Yatim & $1.000 .000<\mathrm{X} \leq 2.000 .000$ & 3 & 80,83 \\
\hline 2 & $\begin{array}{c}\text { Adi } \\
\text { Wiguna }\end{array}$ & Tidak & Yatim & $2.000 .000<\mathrm{X} \leq 4.000 .000$ & 2 & 82,08 \\
\hline 3 & $\begin{array}{l}\text { Ahmad } \\
\text { Zaelani }\end{array}$ & Ada & $\begin{array}{l}\text { Orangtua } \\
\text { lengkap }\end{array}$ & $1.000 .000<\mathrm{X} \leq 2.000 .000$ & 3 & 80,66 \\
\hline 4 & $\begin{array}{c}\text { Desi } \\
\text { Ismiyati }\end{array}$ & Ada & $\begin{array}{l}\text { Orangtua } \\
\text { lengkap }\end{array}$ & $1.000 .000<\mathrm{X} \leq 2.000 .000$ & 4 & 78,09 \\
\hline 5 & $\begin{array}{c}\text { Dimas } \\
\text { Permana }\end{array}$ & Ada & Yatim Piatu & $\mathrm{X} \leq=1.000 .000$ & 3 & 79,18 \\
\hline 6 & $\begin{array}{c}\text { Faisal } \\
\text { Hidayat }\end{array}$ & Tidak & Piatu & $2.000 .000<\mathrm{X} \leq 4.000 .000$ & 1 & 81,09 \\
\hline 7 & $\begin{array}{c}\text { Faridz Dwi } \\
\text { Nurfalah }\end{array}$ & Ada & $\begin{array}{c}\text { Orangtua } \\
\text { lengkap }\end{array}$ & $1.000 .000<\mathrm{X} \leq 2.000 .000$ & 2 & 78,25 \\
\hline 8 & $\begin{array}{c}\text { Gadis } \\
\text { Idhani } \\
\end{array}$ & Ada & Yatim Piatu & $1.000 .000<\mathrm{X} \leq 2.000 .000$ & 3 & 82,14 \\
\hline 9 & $\begin{array}{c}\text { Hariono } \\
\text { Yusuf }\end{array}$ & Tidak & Yatim & $2.000 .000<\mathrm{X} \leq 4.000 .000$ & 1 & 81,71 \\
\hline 10 & $\begin{array}{c}\text { Indah } \\
\text { Permata } \\
\text { Sari }\end{array}$ & Ada & Yatim & $X \leq=1.000 .000$ & 2 & 81,78 \\
\hline
\end{tabular}

Sumber: Wakil Kepala Sekolah SMKN 1 Ciomas (2018)

2. Kriteria yang diterapkan

Sistem Pendukung Keputusan Penerimaan Beasiswa ini menggunakan beberapa kriteria. Daftar kriteria dapat dilihat pada Tabel.2.

Tabel 2. Kriteria

\begin{tabular}{|c|c|}
\hline Kriteria $(\mathrm{C})$ & Keterangan \\
\hline $\mathrm{C} 1$ & Surat Keterangan Tidak Mampu (SKTM) \\
\hline C2 & Status Anak Dalam Keluarga (SADK) \\
\hline C3 & Penghasilan Orang Tua (PO) \\
\hline C4 & Jumlah Tanggungan Orang Tua (JTO) \\
\hline C5 & $\begin{array}{c}\text { Nilai Rata-Rata Raport Semester Terakhir } \\
\text { (NRRST) }\end{array}$ \\
\hline
\end{tabular}

Sumber: Hasil Penelitian (2018)

3. Membuat rating kecocokan setiap alternatif dengan kriteria

Rating kecocokan setiap alternatif dan kriteria, dinilai dengan 1 sampai 5 seperti terlihat pada Tabel 3. 
Tabel 3. Rating Kecocokan Setiap Alternatif

\begin{tabular}{|c|c|c|}
\hline No & Rating Kecocokan & Nilai \\
\hline 1 & Sangat Buruk (SB) & 1 \\
\hline 2 & Buruk (B) & 2 \\
\hline 3 & Cukup (C) & 3 \\
\hline 4 & Baik (T) & 4 \\
\hline 5 & Sangat Baik (ST) & 5 \\
\hline
\end{tabular}

Sumber: Hasil Penelitian (2018)

Berdasarkan data calon penerima beasiswa dari Tabel 1, data tersebut dibentuk ke rating kecocokan setiap alternatif dengan kriteria. Sehingga nilai kriteria untuk setiap alternatif dapat dilihat pada Tabel 4.

Tabel 4. Data Siswa Dikonversikan Ke Rating Kecocokan Alternatif

\begin{tabular}{|c|c|c|c|c|c|c|}
\hline No & Alternatif & C1 & C2 & C3 & C4 & C5 \\
\hline 1 & A1 & 5 & 3 & 3 & 3 & 4 \\
\hline 2 & A2 & 1 & 3 & 5 & 2 & 4 \\
\hline 3 & A3 & 5 & 5 & 3 & 3 & 4 \\
\hline 4 & A4 & 5 & 5 & 3 & 4 & 3 \\
\hline 5 & A5 & 5 & 2 & 2 & 3 & 3 \\
\hline 6 & A6 & 1 & 3 & 5 & 1 & 4 \\
\hline 7 & A7 & 5 & 5 & 3 & 2 & 3 \\
\hline 8 & A8 & 5 & 2 & 3 & 3 & 4 \\
\hline 9 & A9 & 1 & 3 & 5 & 1 & 4 \\
\hline 10 & A10 & 5 & 3 & 2 & 2 & 4 \\
\hline
\end{tabular}

Sumber: Hasil Penelitian (2018)

4. Normalisasi Matriks Keputusan (X)

Langkah selanjutnya melakukan proses normalisasi matriks keputusan (X), dalam normalisasi terdapat 2 rumus yang berbeda sesuai dengan atribut yaitu, atribut keuntungan (benefit) dan atribut biaya (cost).

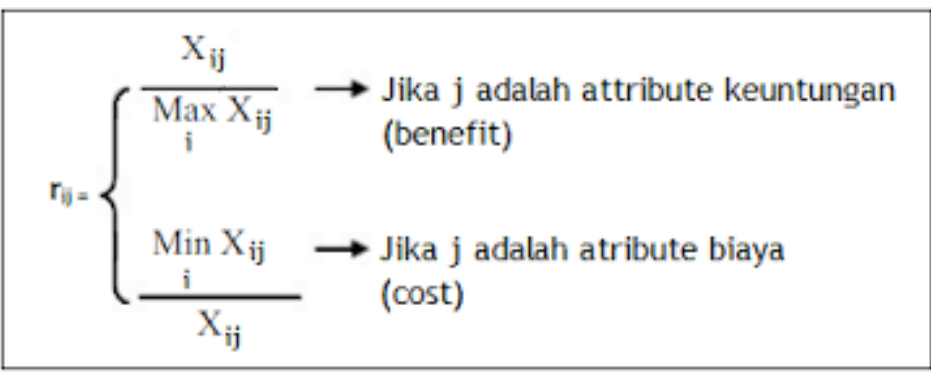

Gambar 4. Rumus Keuntungan (Benefit) Dan Atribut Biaya (Cost) Sumber: Nofriansyah (2014:11) 

Alternatif 1
$\mathrm{r} 11=5 / 5=1$
$\mathrm{r} 12=2 / 3=0,66$
$\mathrm{r} 13=2 / 3=0,66$
$\mathrm{r} 14=3 / 4=0,75$
$\mathrm{r} 15=4 / 4=1$
Alternatif 4
$\mathrm{r} 41=5 / 5=1$
$\mathrm{r} 42=2 / 5=0,4$
$\mathrm{r} 43=2 / 3=0,66$
$\mathrm{r} 44=4 / 4=1$
$\mathrm{r} 45=3 / 4=0,75$
Alternatif 7
$\mathrm{r} 71=5 / 5=1$
$\mathrm{r} 72=2 / 5=0,4$
$\mathrm{r} 73=2 / 3=0,66$
$\mathrm{r} 74=2 / 4=0,5$
r75 $=3 / 4=0,75$
Alternatif 10
$\mathrm{r} 101=5 / 5=1$
$\mathrm{r} 102=2 / 3=0,66$
$\mathrm{r} 103=2 / 2=1$
$\mathrm{r} 104=2 / 4=0,5$
$\mathrm{r} 105=4 / 4=1$

Alternatif 2

$\mathrm{r} 21=1 / 5=0,2$
$\mathrm{r} 22=2 / 3=0,66$
$\mathrm{r} 23=2 / 5=0,4$
$\mathrm{r} 24=2 / 4=0,5$
$\mathrm{r} 25=4 / 4=1$

Alternatif 5

$\mathrm{r} 51=5 / 5=1$

$\mathrm{r} 52=2 / 2=1$

$\mathrm{r} 53=2 / 2=1$

r54 $=3 / 4=0,75$

$\mathrm{r} 55=3 / 4=0,75$

Alternatif 8

$$
\begin{aligned}
& \mathrm{r} 81=5 / 5=1 \\
& \mathrm{r} 82=2 / 2=1 \\
& \mathrm{r} 83=2 / 3=0,66 \\
& \mathrm{r} 84=3 / 4=0,75 \\
& \mathrm{r} 85=4 / 4=1
\end{aligned}
$$

Alternatif 3

$$
\begin{aligned}
& \text { r31 }=5 / 5=1 \\
& \text { r32 }=2 / 5=0,4 \\
& \text { r33 }=2 / 3=0,66 \\
& \text { r34 }=3 / 4=0,75 \\
& \text { r35 }=4 / 4=1
\end{aligned}
$$

Alternatif 6

$$
\begin{aligned}
& \text { r61 }=1 / 5=0,2 \\
& \text { r62 }=2 / 3=0,66 \\
& \text { r63 }=2 / 5=0,4 \\
& \text { r64 }=1 / 4=0,25 \\
& \text { r65 }=4 / 4=1
\end{aligned}
$$

Alternatif 9

$$
\begin{aligned}
& \mathrm{r} 91=1 / 5=0,2 \\
& \mathrm{r} 92=2 / 3=0,66 \\
& \mathrm{r} 93=2 / 5=0,4 \\
& \mathrm{r} 94=1 / 4=0,25 \\
& \mathrm{r} 95=4 / 4=1
\end{aligned}
$$

5. Matriks Ternormalisasi (R)

$\mathrm{R}=\left[\begin{array}{ccccc}1 & 0.66 & 0.66 & 0.75 & 1 \\ 0.2 & 0.66 & 0.4 & 0.5 & 1 \\ 1 & 0.4 & 0.66 & 0.75 & 1 \\ 1 & 0.4 & 0.66 & 1 & 0.75 \\ 1 & 1 & 1 & 0.75 & 0.75 \\ 0.2 & 0.66 & 0.4 & 0.25 & 1 \\ 1 & 0.4 & 0.66 & 0.5 & 0.75 \\ 1 & 1 & 0.66 & 0.75 & 1 \\ 0.2 & 0.66 & 0.4 & 0.25 & 1 \\ 1 & 0.66 & 1 & 0.5 & 1\end{array}\right]$

6. Nilai Preferensi (Vi)

Tabel 5. Tingkat Kepentingan Setiap Kriteria

\begin{tabular}{|c|c|c|}
\hline No & Tingkat Kepentingan & Nilai \\
\hline 1 & Sangat Rendah (SR) & 1 \\
\hline 2 & Rendah (R) & 2 \\
\hline 3 & Cukup (C) & 3 \\
\hline 4 & Tinggi (T) & 4 \\
\hline 5 & Sangat Tinggi (ST) & 5 \\
\hline
\end{tabular}

Sumber: Hasil Penelitian (2018) 


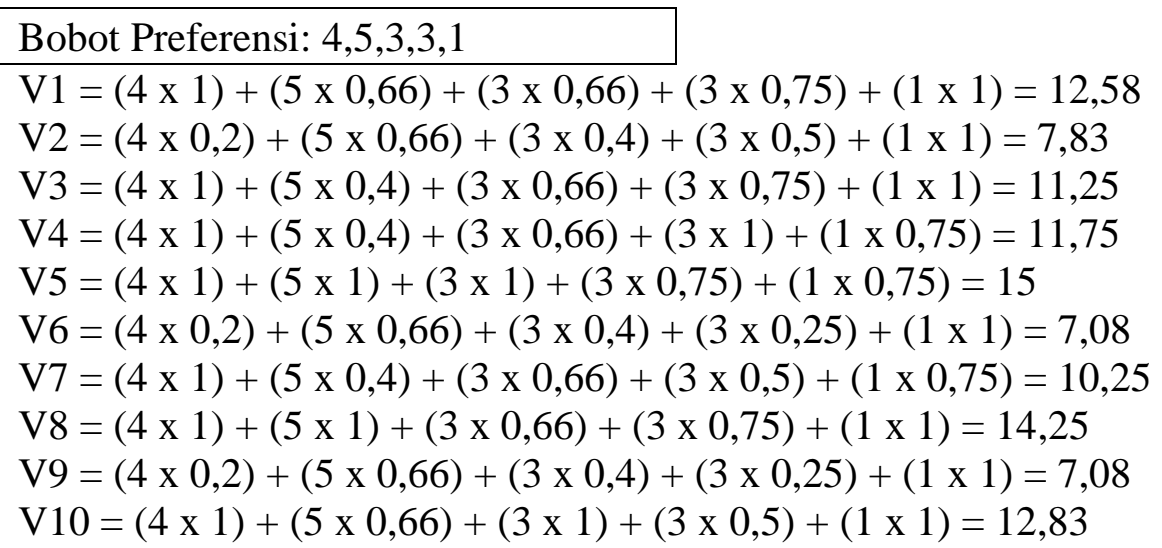

Tabel 6. Hasil Pengujian

\begin{tabular}{|c|c|c|c|c|c|c|c|c|}
\hline \multirow{2}{*}{ No } & \multirow{2}{*}{ Nama } & \multicolumn{7}{|c|}{ Kriteria } \\
\hline & & SKTM & SADK & $\mathrm{PO}$ & JTO & NRRST & HASIL & RANKING \\
\hline 1 & Abdul Hakim & 4 & 3.33 & 2 & 2.25 & 1 & 12.58 & 4 \\
\hline 2 & Adi Wiguna & 0.8 & 3.33 & 1.2 & 1.5 & 1 & 7.83 & 8 \\
\hline 3 & $\begin{array}{l}\text { Ahmad } \\
\text { Zaelani }\end{array}$ & 4 & 2 & 2 & 2.25 & 1 & 11.25 & 6 \\
\hline 4 & Desi Ismiyati & 4 & 2 & 2 & 3 & 0.75 & 11.75 & 5 \\
\hline 5 & $\begin{array}{c}\text { Dimas } \\
\text { Permana }\end{array}$ & 4 & 5 & 3 & 2.25 & 0.75 & 15 & 1 \\
\hline 6 & Faisal Hidayat & 0.8 & 3.33 & 1.2 & 0.75 & 1 & 7.08 & 9 \\
\hline 7 & $\begin{array}{c}\text { Faridz Dwi } \\
\text { Nurfalah }\end{array}$ & 4 & 2 & 2 & 1.5 & 0.75 & 10.25 & 7 \\
\hline 8 & Gadis Idhani & 4 & 5 & 2 & 2.25 & 1 & 14.25 & 2 \\
\hline 9 & Hariono Yusuf & 0.8 & 3.33 & 1.2 & 0.75 & 1 & 7.08 & 10 \\
\hline 10 & $\begin{array}{c}\text { Indah Permata } \\
\text { Sari }\end{array}$ & 4 & 3.33 & 3 & 1.5 & 1 & 12.83 & 3 \\
\hline
\end{tabular}

Sumber: Hasil penelitian (2018)

Setelah melakukan perhitungan, kemudian membuat perankingan dan nilai terbesar adalah A5. Sehingga dapat disimpulkan bahwa alternatif A5 (Dimas Permana) adalah alternatif yang terpilih sebagai alternatif terbaik.

\section{KESIMPULAN DAN REKOMENDASI}

Berdasarkan penelitian sistem pendukung keputusan untuk penerimaan beasiswa dengan metode Simple Additive Weighting (SAW) pada SMKN 1 Ciomas Kabupaten Bogor, maka dapat ditarik kesimpulan bahwa:

1. Metode Simple Additive Weighting (SAW) dapat memberikan alternatif keputusan yang terbaik dalam pengambilan keputusan. 
2. Proses perankingan dilakukan melalui beberapa tahap dengan pemberian nilai kriteria, pembobotan, ranking kecocokan, normalisasi, dan perankingan sehingga menghasilkan nilai dari masing-masing kriteria.

3. Dengan adanya sistem pendukung keputusan untuk penerimaan beasiswa ini dapat dijadikan alat bantu (tools) bagi pihak sekolah sebagai pengambil keputusan dalam memilih siswa penerima beasiswa dengan tepat.

\section{REFERENSI}

Abdillah, Willy. 2018. Metode Penelitian Terpadu Sistem Informasi Pemodelan Teoretis, Pengukuran, dan Pengujian Statistis. Yogyakarta: Andi.

Emanuel, Andi Wahju Rahardjo. 2017. Petunjuk Praktis Metode Penelitian Teknologi Informasi. Yogyakarta: Andi.

Fadilah. (2016). Model Penunjang Keputusan Penentuan Penerima Beasiswa Berprestasi Berbasis SAW di STMIK Banjarbaru. IJSE - Indonesian Journal on Software Engineering, 2(1), 1-6. Retrieved from http://download.portalgaruda.org/article.php?article=435126\&val=8382\&title=Model Penunjang Keputusan Penentuan Penerima Beasiswa Berprestasi Berbasis SAW di STMIK Banjarbaru

Fiqih, M., \& Kusnadi, Y. (2017). Sistem Pendukung Keputusan Pemilihan Dosen Berprestasi Dengan Metode Simple Additive Weighting. Information System For Educators And Professionals, 2(1), 41-50. Retrieved from http://ejournalbinainsani.ac.id/index.php/ISBI/article/view/686/571

Frieyadie. (2017). Penggunaan Metode Simple Additive Weighting Penentuan, 3(1), 17 22.

Helilintar, R. (2016). Penerapan Metode SAW dan Fuzzy Dalam Sistem Pendukung Keputusan Penerimaan Beasiswa in Decision Support System Scholarship. Citec Journal, 3(2), 89-101.

Hidayat, R. (2017). Sistem Pendukung Keputusan Penerima Beasiswa Murid Berprestasi dengan Metode Simple Additive Weighting. Jurnal Sisfotek Global, 7(2), 13-17. Retrieved from https://stmikglobal.ac.id/journal/index.php/sisfotek/article/view/147/151

Kadir, Abdul. 2014. Pengenalan Sistem Informasi Edisi Revisi. Yogyakarta: CV. Andi Offset.

Kadir, Abdul, dan Terra Ch. Triwahyuni. 2013. Pengantar Teknologi Informasi Edisi Revisi. Yogyakarta: CV. Andi Offset.

Kurniawan, H. (2015). Sistem Pendukung Keputusan Menentukan Penerima Beasiswa Berprestasi Menggunakan Fuzzy Multiple Attribute Decision Making ( FMADM ) dengan Metode Saw. Seminar Nasional Teknologi Informasi Dan Multimedia, 91-96. 
Monalisa, S., \& Amri, A. (2015). Analisis Sistem Penentuan Penerimaan Beasiswa Menggunakan Metode Simple Additive Weighting ( Studi Kasus : IJF Rumah Zakat Pekanbaru ), 12(2), 198-203

Novriansyah, Dicky. 2014. Konsep Data Mining Vs Sistem Pendukung Keputusan. Yogyakarta: Deepublish. Diambil dari: https://books.google.co.id/books?id=PoJyCAAAQBAJ\&printsec=frontcover\&source =gbs_ge_summary_r\&cad $=0 \# \mathrm{v}=$ onepage $\& \mathrm{q} \& \mathrm{f}=$ false

Pratiwi, Heny. 2016. Buku Ajar Sistem Pendukung Keputusan. Yogyakarta: Deepublish.

Suliyanto. 2018. Metode Penelitian Bisnis. Yogyakarta: Andi Offset.

Surya, C. (2015). Sistem Pendukung Keputusan Rekomendasi Penerima Beasiswa Menggunakan Fuzzy Multi Attribut Decision Making (FMADM) dan Simple Additive Weighting (SAW). Jurnal Rekayasa Elektrika, 11(4), 149. https://doi.org/10.17529/jre.v11i4.2364

Yulianti, E., Haryanti, T., \& Kurniawati, L. (2014). Sniptek 2014 Sistem Penunjang Keputusan Penerimaan Beasiswa Pegawai Isbn: 978-602-72850-5 -7. Sniptek, (978602-72850-5-7), 39-46.

Zulita, L. N. (2013). Sistem Pendukung Keputusan Menggunakan Metode Saw Untuk Penilaian Dosen Berprestasi (Studi Kasus Di Universitas Dehasen Bengkulu). Jurnal Media Infotama, 9(2), 94-117. Retrieved from http://jurnal.unived.ac.id/index.php/jmi/article/view/65 